\title{
Plasma-Induced Graft Polymerization onto Powders
}

\author{
Yu IRIYAMA ${ }^{* * * *}$ and Shouji IkeDA \\ Research Center, Nippon Paint Co., Ltd., 19-17 Ikedanaka, \\ Neyagawa, Osaka 572, Japan
}

(Received July 5, 1993)

KEY WORDS Plasma / Graft Polymerization / Powders / Plasma-Induced Polymerization /

Low-temperature plasma is a powerful tool for etching, thin-layer formation, surface treatment, etc. in a dry process. Also in a liquid phase, plasma exposure to vinyl monomers leads to the linear polymerization of monomers; this is plasma-induced (or initiated) polymerization $^{1}$. A technique called plasmainduced graft polymerization is a combination of plasma surface treatment and plasmainduced polymerization. The graft polymerization of vinyl monomers is initiated from plasma-treated solid surfaces. The mechanism of graft polymerization is believed to be radical polymerization initiated by radicals on the surface formed by plasma treatment. The formation of radicals on polymeric materials by plasma exposure is well-known, ${ }^{2-4}$ and plasma-induced graft polymerization, therefore, is not a new technique. This technique has been widely applied to polymer films and fibers. ${ }^{5-7}$

In this study, we tried this technique on powders, which has not been reported yet, probably because the handling of powders in plasma apparatus is very difficult. The difficulty comes from the nature of powders: very small diameter and very large surface area. Besides, powders tend to coagulate, which makes uniform and efficient treatment more difficult.
We have invented two types of plasma reactors for powder treatment ${ }^{8-10}$; flaskrotation type and vibration type. Using those reactors, we obtained good results for the improvement of the dispersibility of pigments. ${ }^{8-10}$ We used a modified flask-rotationtype reactor for the plasma-induced graft polymerization on powders. The ultimate goal was the production of ready-dispersed pigments for paint systems and various powders that can be dispersed well in composite materials.

\section{EXPERIMENTAL}

The reactor used was a modified flaskrotation type shown in Figure 1, in which liquid

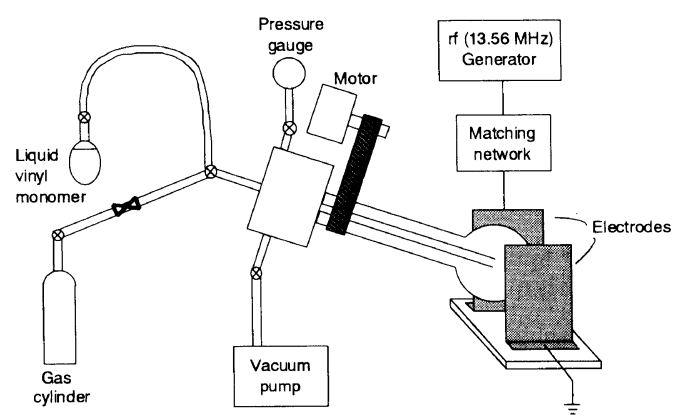

Figure 1. Schematic illustration of the apparatus used for plasma-induced graft polymerization on powders.

* Current address: Department of Chemistry, Yamanashi University, 4-4-37 Takeda, Kofu 400, Japan.

** To whom all correspondence should be addressed. 
monomers are introduced into a flask after plasma treatment of powders without breaking the vacuum.

The powders used were organic and inorganic pigments: titanium dioxide $\left(\mathrm{TiO}_{2}\right.$, rutile), quinacridone red $(\mathrm{QR})$, and carbon black (CB). The monomers were a mixture of four vinyl monomers: methacrylic acid (MAA), methyl methacrylate, ethyl acrylate, and 2-hydroxyethyl acrylate $(1: 3: 3: 3$ in volume ratio). The polymer of this monomer mixture had a typical formula for a water-borne paint system.

Radio-frequency $(13.56 \mathrm{MHz})$ plasma was made with oxygen gas inside the flask $(500 \mathrm{ml})$ where about $200 \mathrm{ml}$ of powders had been placed. During treatment, the flask was rotated for uniform treatment. After plasma treatment, $20 \mathrm{ml}$ of the monomer mixture were introduced on the powders. The powder-monomer mixture was kept at room temperature for three days under vacuum.

Conversion of the monomer mixture to the graft polymer was calculated by weight difference of the product mixture before and after heating at $105^{\circ} \mathrm{C}$ for $3 \mathrm{~h}$. Under this condition, which is specified in the Japanese Industrial Standard-K5400, unreacted monomers can be removed.

\section{RESULTS AND DISCUSSION}

Figure 2 shows the relationship between graft-polymerization conversion and polymerization time on $\mathrm{TiO}_{2}, \mathrm{QR}$, and CB. The powders were treated with $\mathrm{O}_{2}$ plasma of $100 \mathrm{~W}$ at $67 \mathrm{~Pa}$ for $60 \mathrm{~min}$. The polymerization time was the period after the monomer mixture has been introduced to the plasma-treated powders. As shown in this figure, the polymerization rate was very low, but the conversion increased with polymerization time. This low-temperature polymerization, a unique feature of plasma-induced polymerization, is particularly suitable for powders, because most powders coagulate easily at elevated tempera-

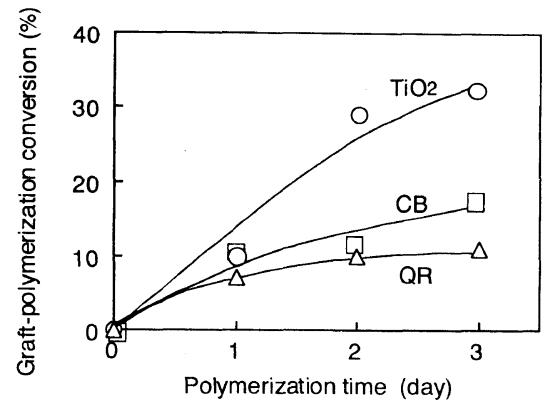

Figure 2. Graft-polymerization conversion of the monomer mixture on $\mathrm{O}_{2}$-plasma-treated $\mathrm{TiO}_{2}, \mathrm{QR}$, and $\mathrm{CB}$.

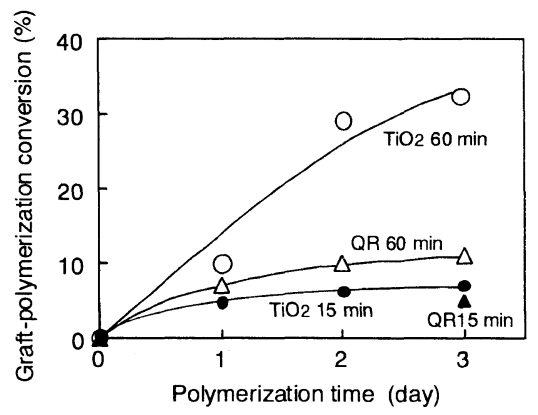

Figure 3. Dependence of graft-polymerization conversion of the monomer mixture on $\mathrm{O}_{2}$-plasma treatment time for $\mathrm{TiO}_{2}$ and $\mathrm{QR}$. Numbers in min denote plasma treatment times.

ture. Since no polymer was found on powders without plasma treatment, the polymerization is believed to be initiated from the surface of the plasma-treated powders. The active species that initiate the polymerization must be radicals because radicals are usually formed on a surface by plasma exposure and monomers are all radical-polymerizable vinyl monomers. However, it is still unknown how $\mathrm{O}_{2}$ plasma created radicals on inorganic surfaces and what kind of radicals are formed on the powder surfaces.

Figure 3 shows the dependence of graftpolymerization conversion of the monomer mixture on plasma treatment time for $\mathrm{TiO}_{2}$ and QR. In plasma surface treatment, very short plasma duration can alter surface properties drastically, which is one of the great features of the plasma technique. Therefore, treatment 
time is usually a less important factor than other plasma conditions for surface properties. In powder treatment, however, usually a much longer treatment time is required..$^{10}$ As shown in Figure 3, the conversions on 15-min-treated powders are far lower than those on corresponding 60-min-treated ones, which suggests that the formation of radicals never saturates within 15-min plasma duration. There is clear dependence of the plasma duration on the polymerization rate. For more efficient graft polymerization, probably a period longer than $60 \mathrm{~min}^{\circ}$ is required. However, ideally, the development of a more efficient plasma powder treatment method is the primary object, which will surely lead to more efficient graft polymerization on powder surfaces.

This slow polymerization is very similar to the plasma-induced polymerization of methyl methacrylate, ${ }^{1}$ in which living polymerization takes place. The similarity, however, does not necessarily imply that the graft polymer is a living polymer. Since the polymerization is initiated from the surface and there should be many propagating radicals around the powders, termination will occur more easily. Therefore, it is rather natural to think that the slow polymerization is due to the high termination rate and possibly low initiation rate. In the initiation of graft polymerization, monomer molecules must contact the powder surface. Therefore, affinity between them may effect the graft polymerization rate.

We compared the graft-polymerization conversion of MAA on $\mathrm{O}_{2}-$ and $\mathrm{NH}_{3}$-plasmatreated $\mathrm{TiO}_{2}$ and QR. Polymerization conversion after one day is indicated in Table I. In general, $\mathrm{O}_{2}$-plasma treatment creates acidic functional groups and $\mathrm{NH}_{3}$ plasma forms basic groups on a surface. From the table, although the polymerization of MAA was very slow, conversions on $\mathrm{NH}_{3}$-plasma-treated powders
Table I. Graft-polymerization conversion of MAA on $\mathrm{O}_{2}$ - and $\mathrm{NH}_{3}$-plasma-treated $\mathrm{TiO}_{2}$ and $\mathrm{QR}$

\begin{tabular}{lcc}
\hline & \multicolumn{2}{c}{$\begin{array}{c}\text { Graft-polymerization } \\
\text { conversion/\% }\end{array}$} \\
\cline { 2 - 3 } & $\mathrm{TiO}_{2}$ & $\mathrm{QR}$ \\
\hline $\mathrm{O}_{2}$ plasma & 2 & 5 \\
$\mathrm{NH}_{3}$ plasma & 8 & 9 \\
\hline
\end{tabular}

were greater than those on $\mathrm{O}_{2}$-plasma treated ones. Since the monomer (MAA) is an acid, a good acid-base interaction between the monomer and the basic surface produced by $\mathrm{NH}_{3}$ plasma might have been attained, which helped to initiate graft polymerization.

The plasma-induced graft polymerization onto powder surfaces was achieved for the first time in this study. We can see, however, there is still some room to improve the plasma treatment method of powders for more efficient graft polymerization.

\section{REFERENCES}

1. Y. Osada, A. T. Bell, and M. Shen, J. Polym. Sci., Polym. Lett. Ed., 16, 309 (1978).

2. C. H. Bamford and J. C. Ward, Polymer, 2, 277 (1961).

3. H. Yasuda, J. Macromol. Sci.-Chem., A10, 383 (1976).

4. M. Kuzuya, A. Noguchi, H. Ito, S. Kondo, and N. Noguchi, J. Phys. Chem., 95,2398 (1991).

5. Y. Osada, Y. Iriyama, and M. Ohta, Nippon Kagaku Kaishi, 831 (1983).

6. Y. Osada and Y. Iriyama, Thin Solid Films, 118, 197 (1984).

7. M. Suzuki, A. Kishida, H. Iwata, and Y. Ikada, Macromolecules, 19, 1804 (1986).

8. K. Tsutsui, K. Nishizawa, and S. Ikeda, J. Coat. Technol., 60 [765], 107 (1988).

9. T. Kobayashi, T. Terada, and S. Ikeda, J. Oil Colour Chem. Assoc., 73, 252 (1990).

10. T. Kobayashi, H. Kageyama, K. Kouguchi, and S. Ikeda, J. Coat. Technol., 64 [809], 41 (1992). 